\title{
Effect of petroleum ether and ethanol fractions of seeds of Abrus precatorius on androgenic alopecia
}

\section{Sukirti Upadhyay, ${ }^{* 1}$ Vinod K Dixit, ${ }^{2}$ Ashoke K Ghosh, ${ }^{1}$ Vijayender Sing $h^{3}$}

${ }^{1}$ College of Pharmacy, IFTM and GB Technical University, India, ${ }^{2}$ Department of Pharmaceutical Sciences, Dr H S Gaur University, India, ${ }^{3}$ School of Pharmacy, KIET, India.

\begin{abstract}
Seeds of Abrus precatorius L., Fabaceae, are commonly used as purgative, emetic, aphrodisiac and in nervous disorder in traditional and folk medicines. In present study petroleum ether and ethanolic extracts of $A$. precatorius seeds are evaluated for reversal of androgen (testosterone by i.m route) induced alopecia in male albino wistar rats and compared to topical administration of standard antiandrogenic drug finasteride for 21 days. The results were reflected from visual observation and histological study of several skin sections via various parameters as anagen to telogen ratio and follicle density $/ \mathrm{mm}$ area of skin surface. The animal of group 1 who were treated with only testosterone became alopecic on visual observation. Animals of Group 2, 3 and 4 who were treated with finasteride, petroleum ether and ethanolic extract of seed respectively topically along with testosterone (i.m) did not developed alopecia. To investigate the mechanism of observed activity, in vitro experiments were performed. Inhibition of $5 \alpha-$ reductase activity by extracts and finasteride suggest that they reversed androgen induced alopecia by inhibiting conversion of testosterone to dihydrotestosterone (potent androgen responsible for androgenic alopecia). So it may be concluded that petroleum ether and ethanolic extract of $A$. precatorius seed posses anti androgenic alopecia activity due to inhibition of $5 \alpha$-reductase enzyme.
\end{abstract}

Revista Brasileira de Farmacognosia Brazilian Journal of Pharmacognosy 22(2): 359-363, Mar./Apr. 2012

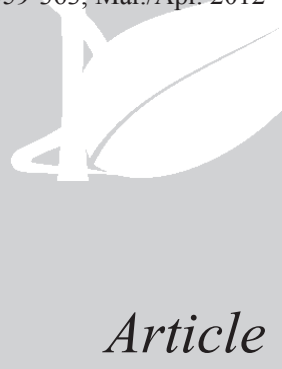

Received 20 Dec 2010

Accepted 1 Aug 2011

Available online 5 Dec 2011

Keywords: Abrus precatorius alopecia androgenic $5 \alpha$-reductase rats seeds

ISSN 0102-695X http://dx.doi.org/10.1590/S0102695X2011005000221

\section{Introduction}

Hair cosmetics and medicaments constitute one of the major parts in global market. Hundreds of hair growth products are available in the markets and these are prepared by combination of one or more herbal drugs. (Ali \& Ansari, 1997). Natural remedies have been used for centuries in treating alopecia (Ayyanar \& Ignacimuthu, 2005; Hoermann \& Korting, 1994). In androgenic alopecia it is assumed that the genetically predisposed hair follicles are the target for androgen-stimulated hair follicle miniaturization, leading to gradual replacement of large, pigmented hairs (terminal hairs) by barely visible, depigmented hairs (vellus hairs) in affected areas (Paus \& Costeralis, 1999). It is dihydrotestosterone mediated process, characterized by continuous miniaturization of androgen reactive hair follicles and accompanied by per follicular fibrosis of follicular units in histological examination (Yoo et al., 2006). Androgenic alopecia results in a decrease in hair follicle size accompanied by a decrease in the duration of anagen and an increase in the percentage of hair follicles in telogen (Cotsarelis \& Millar, 2001).
Finastride, a synthetic antiandrogenic drug is marketed for Benign prostrate hyperplasia and androgenic alopecia and the mechanism involved is inhibition of $5 \alpha$-reductase activity (Tian et al., 1994) Finasteride also has been used topically to treat androgenetic alopecia (Mazzarella et al., 1997). For the treatment of androgen related disorders like androgenetic alopecia, finasteride has been approved by USFDA (Libecco \& Bergfeld, 2004), but there are many side effects associated with finasteride. As Cuscuta reflexa Roxb was found effective in androgen induced alopecia (Pandit et al., 1998), the study here was focused on the seed extracts of Abrus precatorius L., a leguminous plant of the Fabaceae family that is also called Indian liquorice, jequirity, crab eye, glycyrrhizin glabra and olho de Pombo, among others. The plant grows widely in fairly dry climates of tropical and subtropical regions, such as India, Sri Lanka, Nigeria and the West Indies. The leaves, roots and seeds of $A$. precatorius are used for medicinal purposes, a practice most probably dating back to antiquity (Ross, 2003). The seeds contain campesterol, cholesterol, palmitic acid, linoceric acid, linoleic acid, oleic acid, $\beta$-sitosterol, stigmasterol, trigonellin, brassicasterol (Ross, 2003). 


\section{Material and Methods}

\section{Plant material}

Seeds of Abrus precatorius L., Fabaceae, were collected in the month of November from Dr HS Gaur University, Sagar (23N50 78E43) campus. The plant was identified by Dr Pradeep Tiwari, at Department of Botany of the same university and a voucher specimen no (Bot/ $\mathrm{H} / 3031)$ has been preserved for further references. The material was dried under sunlight and carefully reduced to coarse powder and stored in airtight container after sieving them through \# 40 mesh.

\section{Preparation of extracts}

Coarsely powdered drug was taken in a Soxhlet apparatus and extracted with petroleum ether $\left(60-80{ }^{\circ} \mathrm{C}\right)$ till complete extraction. The solvent from the extract was recovered under reduced pressure and its yield was $1.6 \%$ w/w. Then successively extracted with $99.9 \%$ ethanol and the yield was $1.8 \% \mathrm{w} / \mathrm{w}$.

\section{Chromatographic characterization}

For experiment, petroleum ether seed extract of A. precatorius was characterized by TLC on precoated silica gel G plate $(10 \times 10)($ E. Merk, Germany) developed in toluene:ethyl acetate $(95: 5 \mathrm{v} / \mathrm{v})$ as mobile phase gave best resolution after derivatization with Lieberman Burchard reagent. Steroidal component was present in this as proved by phytochemical analysis. Ethanolic extract was characterized by giving best resolution in n-butanol:ethanol:water $(10: 10: 4.2 \mathrm{v} / \mathrm{v})$ as mobile phase after derivatization with vanillin-sulphuric acid reagent. Flavanoid, alkaloid, carbohydrate, phenolic, protein and amino acid were present in this as proved by phytochemical analysis.

\section{Preliminary skin irritation test}

This test was carried out by protocol mention in ASTM (1998). The petroleum ether and ethanolic extracts of $A$. precatorius applied in a concentration of up to $10 \%$ for seven days on shaved skin surface of wistar rats, did not show any irritation or erythema on skin surface. Thus the prepared extracts were considered safe for topical administration (Roy et al., 2008). A. precatorius seeds are known for their toxicity but both petroleum ether and ethanolic extract do not contain toxic principles (Humpreys, 1969; Niyogi \& Rieders, 1969).

\section{In vivo studies on hair growth against testosterone induced alopecia}

\section{Animals}

The protocol for experimentation was approved by Institutional Animal Ethics Committee of Dr H S Gour University, Sagar, India in form \#08/3870. Male albino rat (2-3 months) were housed in cages at room temperature $\left(26 \pm 2{ }^{\circ} \mathrm{C}\right)$ and were fed on standard diet with free access to water.

Preparation of finasteride, testosterone and extract solutions

Marketed preparation of testosterone suspension named Aquavirion (1 mL) was diluted up to $5 \mathrm{~mL}$ with water for injection this was able to produce the concentration of $5 \mathrm{mg} / \mathrm{mL}$. The $2 \%$ standard finasteride solution and $1 \%$ extract solutions was prepared in vehicle (ethanol:propylene glycol:water 8:1:1).

Treatment of animal for study

The method reported by Matias et al. (1989) was followed with slight modification. In brief, the rats were divided in four groups of six rats each. Rats of all the groups were administered testosterone dose $(0.1 \mathrm{~mL})$ intramuscularly. Animals of group 2, 3 and 4 were also given topical application of $0.4 \mathrm{~mL}$ finasteride, petroleum ether and ethanolic extract of seed respectively on dorsal skin surface once a day for 21 days ( Table 1). After this period, one rat from each group were selected randomly and sacrificed. The difference in growth of hair in each group was noticed by visual observations and was recorded by photographs. Skin biopsy was also undertaken from balding site and the cyclic phase of hair follicles (Anagen, Telogen) and follicular density was determined with the help of ocular micrometer.

Table 1. Percent hair cycle (\%) stage of animals on $21^{\text {st }}$ day after treatments.

\begin{tabular}{|c|c|c|c|c|}
\hline \multirow{2}{*}{ Group No } & \multirow{2}{*}{ Treatments } & \multicolumn{3}{|c|}{ Percent hair cycle Stages } \\
\hline & & Telogen(Te) & Anagen(A) & $\mathrm{A} / \mathrm{Te}$ \\
\hline 1 & Testosterone (i.m.) only & $83.1 \pm 0.5667$ & $16.9 \pm 0.5667$ & 0.2034 \\
\hline 2 & $\mathrm{~T}($ i.m. $)$ finasteride $(2 \%)$ topically & $52.4 \pm 0.6864 * * *$ & $47.6 \pm 0.6864 * * *$ & 0.9084 \\
\hline 3 & $\mathrm{~T}(i . m)+$. petroleum ether seed extract in $1 \%$ vehicle topically & $45.2 \pm 0.5735 * * *$ & $55.8 \pm 0.5774 * * *$ & 1.2168 \\
\hline 4 & $\mathrm{~T}($ i.m. $)+$ ethanolic seed extract ether seed extract in $1 \%$ vehicle topically & $34.4 \pm 0.5207 * * *$ & $65.3 \pm 0.5175 * * *$ & 1.8983 \\
\hline
\end{tabular}

All four groups contain six animals; $\mathrm{n}=$ skin sections number $=10$; $\mathrm{T}$ : testosterone; values are mean $\pm \mathrm{SEM}$, with significant $* * * p<0.001$ value as compared to control. 
In vitro studies on enzymatic activity

\section{Preparation of enzyme solution}

Human prostate (about $195 \mathrm{mg}$ ) supplied from a local hospital was cut in small pieces and homogenized in $10 \mathrm{~mL}$ of medium A (20 mm sodium phosphate, $\mathrm{pH}$ 6.5 , containing $0.32 \mathrm{~g}$ sucrose and $1 \mathrm{mM}$ EDTA). The homogenate was centrifuged at $4000 \mathrm{x} g$ for $15 \mathrm{~min}$. The supernatant was used as a source of enzyme. The concentration of enzyme in the supernatant was determined by Bradford Method of Protein estimation (Bradford, 1976).

\section{Preparation of test materials}

Testosterone $(1 \mathrm{mM})$, petroleum ether extract (1 $\mathrm{mg} / \mathrm{mL})$, ethanolic extract $(1 \mathrm{mg} / \mathrm{mL})$ and finasteride $(10$ $\mu \mathrm{g} / \mathrm{mL}$ ) solution were prepared in ethanol $95 \%$ with gentle heating wherever necessary. The EDTA solution $(10 \mathrm{mg} /$ $\mathrm{mL}$ ) was made in distilled water.

enzyme

Determination of optimum concentration of

It was determined by keeping the concentration of substrate constant and varying the concentration of enzyme. Testosterone solution $(1 \mathrm{mM})$ was prepared in ethanol. Reaction mixture $(1 \mathrm{~mL})$ was prepared by adding testosterone solution $(0.1 \mathrm{~mL})$, enzyme solution (0.1-0.9 $\mathrm{mL})$, and sodium phosphate buffer $(20 \mathrm{mM})$. The reaction mixture was incubated at $37{ }^{\circ} \mathrm{C}$ for $1 \mathrm{~h}$. The reaction was terminated by addition of $2 \mathrm{~mL}$ of ethyl acetate. The reaction mixture was then shaken vigorously for $1 \mathrm{~min}$ and the ethyl acetate layer was separated. It was evaporated to dryness, and the residue dissolved in $2 \mathrm{~mL}$ of methanol. Testosterone content in methanolic solution was estimated by high performance liquid chromatography (HPLC, Shimadzu, Column C 18).

Determination of inhibitory concentrations of petroleum ether and ethanolic extract of A. precatorius

The reaction mixture $(1.5 \mathrm{~mL})$ was made by adding $0.1 \mathrm{~mL}$ of testosterone solution, $0.1 \mathrm{~mL}$ of EDTA solution,0.1-0.5 mL of petroleum ether extract/ethanolic extract/finasteride solutions groups, optimum amount of enzyme solution (i.e., $0.5 \mathrm{~mL})$, and sodium phosphate (20 $\mathrm{mm}$ ), to a final volume of $1.5 \mathrm{~mL}$. Reaction mixture was incubated at $37^{\circ} \mathrm{C}$ for $60 \mathrm{~min}$, and reaction was terminated by addition of $3 \mathrm{~mL}$ of ethylacetate. The mixture was vortexed for $1 \mathrm{~min}$; was separated and evaporated to dryness, residue was dissolved in methanol and volume made up to $2 \mathrm{~mL}$ with methanol. The residual testosterone content in methanol was determined by HPLC. The column was eluted isocratically with a mobile phase of methanol:water (80:20) at a flow rate of $1.0 \mathrm{~mL} / \mathrm{m}$ (Purdon et al., 1997).

\section{Statistical analysis}

Data are reported as mean \pm SEM. Statistical analysis of data was carried out by one way ANOVA comparing all test group (group 2, 3 and 4) versus negative control (group 1) followed by Dunnett's test using Instat v 2.1 software.

\section{Results}

In vivo hair growth studies against testosterone induced alopecia

\section{Qualitative study}

Alopecia proceeds via cranial to caudal region in rodents (Parthasarathy et al., 1992) The animals of group 1 showed diffuse alopecia. Loss of hair from dorsal portion of rat was clearly visible after 21 days treatment with testosterone. The observation was better in animals of group 2; no signs of alopecia were developed. In animals of group 3 the alopecic conditions was not visible and showing that the extract successfully prevented and blocked testosterone induced hair loss. Animal of group 4 also showed no sign of alopecia as their hair did not become thin on dorsal skin (Figure 1).

\section{Quantitative study}

In the present investigations alopecia was induced in rat by administration of testosterone. Testosterone is required, along with a genetic predisposition, for androgenetic alopecia to develop in men (Hamilton, 1942) Microscopic examination of skin sections of group 1 animals revealed that testosterone treatment cause miniaturization of hair follicles. The follicles had bulbous appearance and were short (Figure 2). Several hair follicles were in telogen phase. The effect of testosterone on miniaturization of hair follicle was blocked by administration of topical finasteride, petroleum ether and ethanolic extract of seed in group 2, 3 and 4 animals respectively. The number of follicles in anagen phase was considerable and fewer follicles in telogen phase were observed. A/Te ratio was significantly affected by finasteride and extracts which was observed in skin sections of various groups (Table 1) (Figure 2A, B and C).

The follicular density i.e. no of follicles in $\mathrm{mm}$ of skin surface. The follicular density also showed that both seed extracts treated animal had denser hair follicle (Figure 3). 


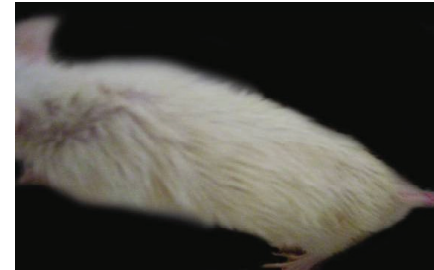

A

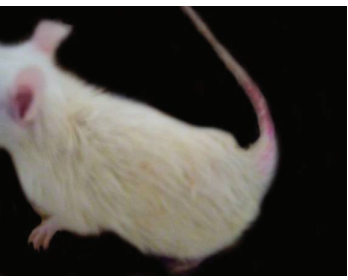

B
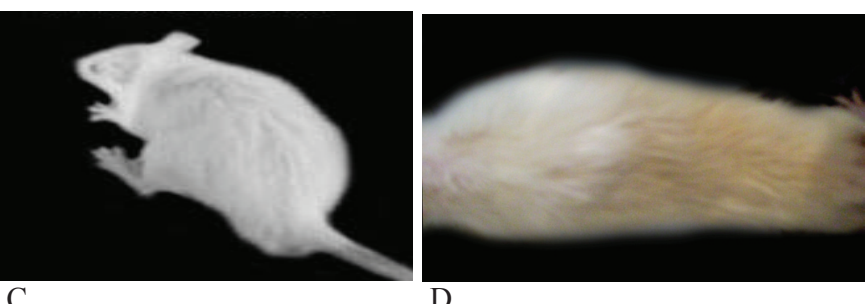

$\mathrm{D}$

Figure 1. A. The animal shows hair loss from cranial reason and hair become thin on dorsal skin, i.e. alopecia condition is visible in group 1 animal due to testosterone administration; B. Animals of group 2 do not develop alopecia on 21 days treatment with testosterone due to simultaneous treatment with finasteride; C. Animals of group 3 do not become alopecic as petroleum ether extract of seed combat testosterone effect; Animals of group 4 also do not develop alopecia as ethanolic extract of seed successfully antagonize testosterone effect.

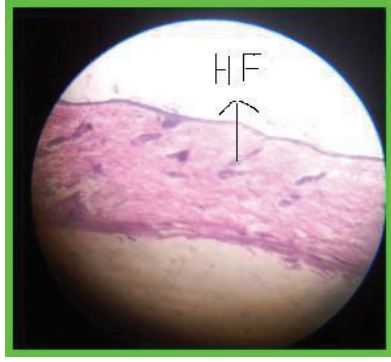

A

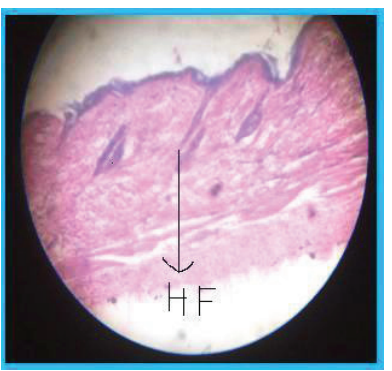

B

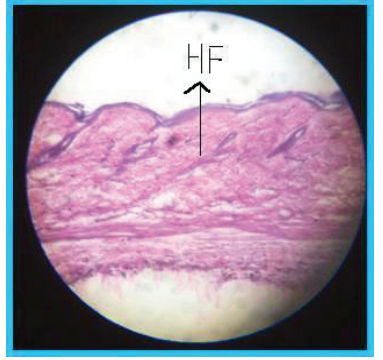

$\mathrm{C}$

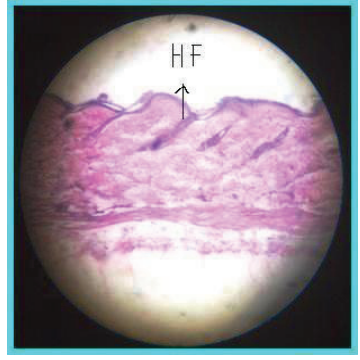

D

Figure 2. A. Skin section of Group 1 animals showed maximum telogenic hair follicle leading to alopecia; B. Skin section of Group 2 animal shows hair follicles in anagenic (hair growing stage); C. Skin section of Group 3 animal shows more hair follicles in anagenic stage than finasteride treated group 2 animals; D. Skin sections of Group 4 animals showed maximum no of anagenic follicles. $\mathrm{HF}=$ hair follicle.

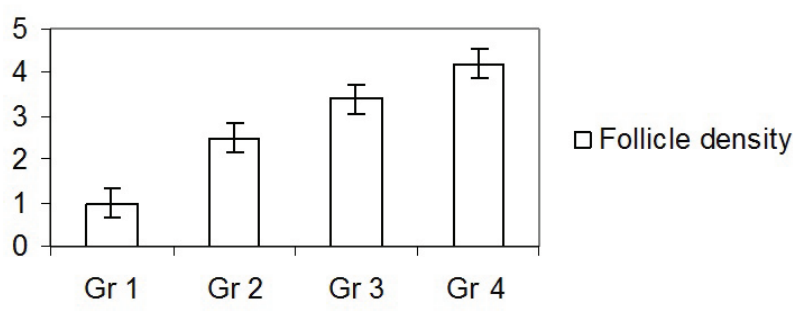

Figure 3. Follicle density is maximum in group four animals followed by group 3 and 2 while group 1 animals showed minimum follicle density. Gr: group.

\section{Determination of IC50}

The optimum concentration of the enzyme was found at $0.5 \mathrm{~mL}(230.9 \mu \mathrm{g})$. Varying concentrations of test substances were incubated with a constant amount of testosterone and enzyme in reaction mixture, and the residual testosterone content was determined after termination of reaction with ethyl acetate. The residual testosterone content in reaction mixture increased with increasing concentration of petroleum ether extract, ethanolic extract and finasteride. The IC50 values calculated for petroleum ether extract, ethanolic extract, and finasteride were $1.78 \mathrm{mg}, 1.70 \mathrm{mg}$ and $0.72 \mu \mathrm{g}$ showed enzyme inhibitory activity if these compounds.

\section{Discussion}

As evident from above data, the activity of petroleum ether and ethanolic extract of $A$. precatorius is better than finasteride. The alopecia, induced in the rat by testosterone was counteracted when finasteride, petroleum ether or ethanolic extract of seed were administered. The predominance of hair follicle in anagenic growth phase indicates reversal of androgen induced hair loss in finasteride petroleum ether and ethanolic extract treated groups. Conversion of testosterone to dihydrotestosterone, which is a more potent androgen, results in miniaturization of hair follicle and change in cyclic phase of hair growth cycle, which leads to androgenic alopecia. The enzyme $5 \alpha$-reductase type 2 is the key enzyme responsible for conversion of testosterone to dihydrotestosterone. (Kaufman, 2002). The prostate is rich in enzyme $5 \alpha-$ reductase type 2 , and prostate homogenate demonstrates conversion of testosterone to dihydrotestosterone in reaction mixtures (Steers, 2001). Both extracts successfully blocks the conversion of testosterone into dihydrotestosterone on comparison with standard finasteride. As dihydroxy testosterone is responsible for androgenic alopecia so it may concluded that both extracts may function similar to finasteride in combating testosterone effect. The ethanolic extract of seed on intraperitoneally administration also lowers the testosterone levels (Jahan et al., 2009). Thus 
A. precatorius seed ethanolic and petroleum ether extract is considered a useful preparation for topical use in commercial formulations for androgenic alopecia and other androgen related disorders.

\section{Acknowledgements}

One of the author, $\mathrm{SU}$, is thankful to university grants commission for providing financial support and managing director R M Dubey for allowing part of this work to performed in IFTM.

\section{References}

Ali M, Ansari S H 1997. Hair care and herbal drugs. Indian J Nat Prod 13: 3-5.

Ayyanar MA, Ignacimuthu 2005. Medicinal plants used by the tribal of Tirunelvehi hills, Tamil Nadu to treat poisonous bites and skin disease. Ind J Trad Know 4: 229-336.

ASTM 1998. Standard practice for testing biomaterials in rabbits for primary skin irritation, Philadelphia: American Society for Testing of Materials, F 719-781: 178-179.

Bradford MM 1976. A rapid and sensitive method for the quantitation of microgram quantities of protein utilizingthe principle of protein-dye binding. Anal Biochem 72: 248-254.

Cotsarelis G, Millar SE 2001. Towards a molecular under standing of hair loss and its treatment. Trends $\mathrm{Mol} \mathrm{Med}$ 7: 293-301

Hamilton JB 1942. Male hormone stimulation is a prerequisite and an incitant in common baldness. Am J Anat 71: 451480.

Hoermann HP, Korting HC 1994. Evidence for the efficacy and safety of topical herbal drugs in dermatology, antiinflammatory agents. Phytomedicine 1: 161-171.

Humpreys DJ 1969. The toxic factors of the seeds of $A$. precatorius. Phytochemistry 8: 2397-2400.

Jahan S, Saeed N, Ijlal F, Khan MA, Zafar M,Abbasi AM 2009. Histomorphological study to evaluate anti fertility effect of A. precatorius L. in adult male mice. J Med Plants Res 3: 1021-1028.

Kaufman KD 2002. Androgens and alopecia. Mol Cell Endocrinol 198: 89-95.

Libecco JF, Bergfeld WF 2004. Finasteride in the treatment of alopecia. Expert Opin Pharmaco 5: 933-940.

Matias JR, Malloy V, Orentreich N 1989. Animal models of androgen-dependent disorders of the pilosebaceous apparatus. 1. The androchronogenetic alopecia (AGA) mouse as a model for male-pattern baldness. Arch
Dermatol Res 281: 247-253.

Mazzarella F, Loconsole F, Cammisa A, Mastrolonardo M, Vena G 1997. Topical finasteride in the treatment of androgenic alopecia. Preliminary evaluations after a 16month therapy course. J Dermatol Treat 8: 189-192.

Niyogi SK, Rieders F 1969 .Toxicity studies with fractions from A. precatorius seed kernals. Toxicon 7: 211-216.

Pandit S, Chauhan NS, Dixit VK 2008. Effect of Cuscuta reflexa Roxb on androgen-induced alopecia. J Cosmet Dermatol 7: 199-204.

Parthasarathy S, Malloy V, Matias J, Massardo S, Bariether L, Kotes J, Orentreich N 1992. The in-vitro transformation of testosterone and the ability of its $5 \alpha$-reduced 17 beta hydroxylated metabolites, to induce hair loss in the androchronogenetic alopecia (AGA) mouse (abstract). $J$ Invest Dermatol 98: 4.

Paus R, Costeralis CG 1999.The biology of hair follicle. New Engl J Med 341: 493-497.

Purdon MP, Lehman-McKeeman LD 1997. Improved highperformance liquid chromatographic procedure for the separation and quantification of hydroxytestosterone metabolites. J Pharmacol Toxicol 37: 67-73.

Ross IA 2003. Medicinal plants of the world. Chemical constituents, traditional and modern medicinal uses. Humana Press 1: 15-31.

Roy RK, Mayank T, Dixit VK 2008. Hair growth promoting activity of Eclipta alba in male albino rats. Arch Dermatol Res 300: 357-364.

Steers WD 2001. 5 alpha-Reductase activity in the prostate. Urology 58 (6 Suppl. 1): 17-24.

Tian G, Stuart JD, Moss ML, Domanico PL, Bramson HN, Patel IR, Kawdell SH ,Overton LK, Kost TA, Mook RA, Frye SV, Batchelor KW, Wiseman JS 1994. 17ß-(ntert-Butylcarbamoyl)-4-aza- $5 \alpha$-androstan-1-ene-3-one is an active site-directed slow time-dependent inhibitor of

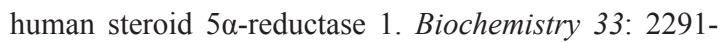
2296.

Yoo G, Kim JS, Lee SR, Pyo HK, Moon HI, Lee JH 2006. Perifollicular fibrosis: Pathogenetic role in androgenetic alopecia. Biol Pharm Bull 29: 1246-1250.

\section{*Correspondence}

Sukirti Upadhyay

College of Pharmacy, IFTM, Moradabad-244 001(UP), India and

G B Technical University, Lucknow (UP), India sukirti_mishra@rediffmail.com,director@iftmmbd.org

Tel.: +919410478954

Fax: +91 5912360818 